\title{
Synthetic Pyridoindole and Rutin Affect Upregulation of Endothelial Nitric Oxide Synthase and Heart Function in Rats Fed a High-Fat- Fructose Diet
}

\author{
Lazaros SALVARAS ${ }^{1}$, Tomas KOVACIC ${ }^{2}$, Pavol JANEGA ${ }^{2,3}$, Boris LIPTAK ${ }^{4}$, Michaela \\ SASVARIOVA ${ }^{1}$, Dominika MICHALIKOVA ${ }^{4}$, Barbara TYUKOS KAPRINAY ${ }^{4}$, Stefan \\ BEZEK $^{4}$, Ruzena SOTNIKOVA ${ }^{4}$, Vladimir KNEZL ${ }^{4}$, Tatiana STANKOVICOVA ${ }^{1}$, Zdenka \\ GASPAROVA ${ }^{4}$
}

${ }^{1}$ Comenius University, Faculty of Pharmacy, Department of Pharmacology and Toxicology, Bratislava, Slovak Republic, ${ }^{2}$ Comenius University and University Hospital, Medical Faculty, Institute of Pathological Anatomy, Bratislava Slovak Republic, ${ }^{3}$ Slovak Academy of Sciences, Centre of Experimental Medicine, Institute of Normal and Pathological Physiology, Bratislava, Slovak Republic, ${ }^{4}$ Slovak Academy of Sciences, Centre of Experimental Medicine, Institute of Experimental Pharmacology and Toxicology, Bratislava, Slovak Republic

Received February 26, 2021

Accepted August 10, 2021

Epub Ahead of Print October 30, 2021

\begin{abstract}
Summary
Metabolic syndrome (MetS) belongs to the serious health complications expanding in cardiovascular diseases, obesity, insulin resistance, and hyperglycemia. In this study, hypertriacylglycerolemic rats fed a high-fat-fructose diet (HFFD) were used as an experimental model of MetS to explore the effect of tested compounds. Effects of a new prospective pyridoindole derivative coded SMe1EC2 and the natural polyphenol rutin were tested. Endothelial nitric oxide synthase (NOS3) and nuclear factor kappa B (NF-kB) expression were assessed in the left ventricle immunohistochemically and left ventricle activity was monitored in isolated perfused rat hearts. NOS3 activity in the left ventricle decreased markedly as a result of a HFFD. NOS3 expression was upregulated by both substances. NF-KB expression was increased in the MetS group in comparison to control rats and the expression further increased in the SMe1EC2 treatment. This compound significantly improved the coronary flow in comparison to the control group during reperfusion of the heart followed after ischemia. Further, it tended to increase left ventricular systolic pressure, heart product, rate of maximal contraction and relaxation, and coronary flow during baseline assessment. Moreover, the compound SMe1EC2 decreased the sensitivity of hearts to electrically induced ventricular fibrillation. Contrary to this rutin decreased coronary flow in reperfusion. Present results suggest that despite upregulation of NOS3 by both substances tested,
\end{abstract}

pyridoindole SMe1EC2 rather than rutin could be suitable in treatment strategies of cardiovascular disorders in MetS-like conditions.

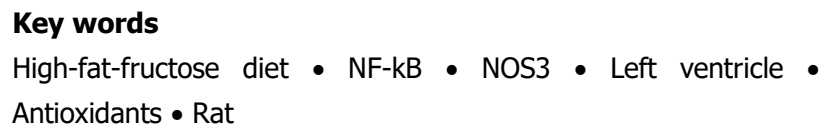

\section{Corresponding author}

Zdenka Gasparova, Slovak Academy of Sciences, Centre of Experimental Medicine, Institute of Experimental Pharmacology and Toxicology, Dubravska cesta 9, 84104 Bratislava, Slovak Republic. E-mail: zdenka.gasparova@savba.sk

\section{Introduction}

Diet, rich in fat and sugar, results in an increased incidence of obesity, cardiovascular diseases (CVD), 2 type diabetes mellitus (DM2T), and metabolic disorders. Metabolic syndrome (MetS) is defined by the presence of at least three components from a cluster of risk factors such as dyslipidemia, hypertension, central obesity, insulin resistance (Reaven 1988) leading to atherosclerosis and endothelial dysfunction (ED) (Grundy 2007). There are traditional cardiovascular biomarkers (LDL- and 
HDL-cholesterol, glucose, etc.), cardiac-specific biomarkers (cardiac troponins, natriuretic peptides, etc.), anatomical and electrophysiological cardiac biomarkers (carotid intima-media thickness, coronary artery calcification, heart rate variability), and gene regulators which may provide insight into disease pathogenesis (Parsanathan and Jain, 2020). We used hereditary hypertriacylglycerolemic (HTG) rats, a suitable model for the study of the MetS (Zicha et al. 2006) fed high-fatfructose diet (HFFD) when almost complete MetS expression was achieved (Kaprinay et al. 2016, 2017). HTG rats fed a high-fat diet (HFD) had been reported to have elevated levels of triacylglycerols (TG), total cholesterol, LDL-cholesterol, and blood pressure, decreased HDL-cholesterol level, and impaired glucose tolerance (Kaprinay et al. 2016, Bezek et al. 2017), steatotic liver, increased aortal intima-media wall thickness (Gasparova et al. 2018), increased expression of inflammatory markers, interleukin-6 (IL-6) and tumor necrosis factor- $\alpha$ (TNF- $\alpha$ ) (Bezek et al. 2017), and markers of oxidative stress (OS) (Kaprinay et al. 2016). Moreover, HFD combined with fructose potentiated negative effects on rat heart and vessel function parameters thus a more appropriate animal model for MetS has been developed, which has been achieved by a combination of hypertriacylglycerolemia and the effect of a diet rich in fat and fructose (Kaprinay et al. 2017, Michalikova et al. 2019, Liptak et al. 2019). The main mechanism for the pathogenesis of CVD seems to be ED. This is present in patients with DM2T, obesity, and MetS. The endothelium produces vasoactive substances and modulates the proliferation and injury response of the vascular smooth muscle layer (Huang 2009). A common feature of ED is the reduced bioavailability of nitric oxide (NO) in the vasculature. In hypertension, endothelial nitric oxide synthase (NOS3) produces less NO and could be one of the contributing factors to the increased peripheral vascular resistance. Agonist-induced $\mathrm{Ca}^{2+}$ entry is essential for the activation of NOS3 (Boudaka et al. 2019). A combination of downregulation of NOS3, changes in the bioavailability of $\mathrm{NO}$, and the resulting OS of the endothelium represent a key pathological mechanism in CVD. This can lead to activation of an inflammatory response and subsequent negative effect on circulation. NOS3 gene deficiency results in hypercoagulability, hypertension, and increased diet-induced atherosclerosis (Huang et al. 1995). Thus OS and ED may be exacerbated by dietary influences. Damaged endothelium is associated with increased blood levels of free fatty acids, inflammatory cytokines IL-6 and
TNF- $\alpha$ (Deanfield et al. 2007), and nuclear factor kappa B $(\mathrm{NF}-\kappa \mathrm{B})$ activation in patients with DM2T (Bierhaus et al. 2001). OS in the presence of risk factors increases activation of redox-dependent transcriptional factors such as NF- $\mathrm{B}$, promoting the development of cardiac dysfunction and remodeling. However, NF- $\kappa \mathrm{B}$ also acts as a protective factor against programmed cell death by inducing anti-apoptotic genes (Beg and Baltimore 1996).

The cellular and molecular mechanisms underlying the pathogenesis of the MetS are not completely understood. A recent search for new potential drugs in the treatment of MetS includes synthetic and natural substances with multiple beneficial effects. We investigated an effect of a synthetic pyridoindole coded SMe1EC2, (2-ethoxy carbonyl-8-methoxy-2,3,4,4a,5,9bhexahydro-1 $H$-pyrido[4,3-b]indole), selected on its described antioxidant, cardioprotective, and antilipoperoxidation effects (Stolc et al. 2006). Modification of the parent molecule stobadine by aromatic electron donor substitution as in the compound SMe1EC2 increases the intrinsic free radical scavenging activity (Juranek et al. 2010). Natural compound rutin was selected based on its TG lowering, antioxidant and antiinflammatory effects in animal models of DM2T (Prince and Kamalakkannan 2006). Increasing evidence indicates that flavonoid-rich foods exert beneficial effects in MetS. Rutin attenuated cardiac remodeling and left ventricular and myocardial dysfunction in streptozotocin-induced diabetes mellitus (Guimaraes et al. 2015). Rutin lowered serum cholesterol level and myocardial necrosis in a diabetes model associated with hyperlipidemia (Krishna et al. 2005), it reduced the infarct size of the myocardium through extracellular signal-regulated kinase $1 / 2$ and protein kinase B signaling pathways in a porcine model of coronary heart disease (Lv et al. 2018). In our previous experiments, rutin improved an aorta relaxation and tended to reduce TG levels in HTG rats fed HFFD (Michalikova et al. 2019). In present work, 1) the impact of diet was investigated on biometric data (body, liver, kidney, and heart weights), 2) heart dysfunctions and 3 ) change of expression of NOS3 and NF- $\mathrm{BB}$, the key regulators of cardiac function, were determined, and 4) the impact of treatment by two selected substances was investigated in HTG rats fed HFFD.

\section{Methods}

Animals, diets, compounds

The experiments were under the Guide for the 
care and use of laboratory animals and they were approved by the State Veterinary and Food Administration of the Slovak Republic (No. 3635/14221) and by the Ethical Committee of the Centre of Experimental Medicine, Slovak Academy of Sciences (CEM SAS), Bratislava. The design of the experiment is shown in Fig. 1. Hereditary HTG male rats from the Department of Toxicology and Breeding of Laboratory Animals of CEM SAS were used. HTG rats were fed HFFD (enriched with $1 \%$ cholesterol, $7.5 \%$ pork lard, and $10 \%$ fructose). Wistar male rats $(n=10), 4$ weeks old, fed standard pellets for rodents, served as a healthy negative control group (C), as the HTG rats were selected from the Wistar stem line. HTG rats $(n=30), 4$ weeks old, were randomly divided into three groups $(n=10)$ and fed a modified diet from weaning. After 13 weeks, HTG rats in all three groups had changed the HFFD to a normal diet and two groups of them received the drug treatment for the next 5 weeks. One group of HTG rats fed HFFD for 13 weeks was untreated over the next 5 weeks and received only a vehicle, serving as a positive control (HFFD). The animals had a $12 \mathrm{~h}$ light/12 h dark cycle and food and water ad libitum. They were weighed once a week and consumption of pellets was recorded daily. The animals were anesthetized with diethyl ether and decapitated at the age of 22 weeks. Hearts, livers, and kidneys were weighed.

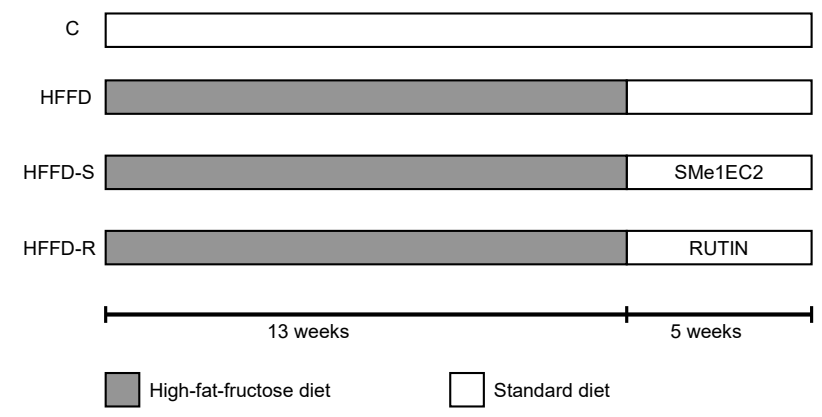

Fig. 1. Design of experiment. Four experimental groups of rats, number per group $n=10, C$ - control group of Wistar rats fed standard diet during 18 weeks, HFFD - untreated group of hypertriacylglycerolemic (HTG) rats fed 13 weeks with high-fatfructose diet (HFFD) followed by 5 weeks on standard diet, HFFD-S - group of HTG rats fed 13 weeks HFFD followed by 5 weeks on standard diet and treated daily with the compound SMe1EC2 (10 mg/kg), HFFD-R - group of HTG rats fed 13 weeks HFFD followed by 5 weeks on standard diet and treated daily with rutin $(100 \mathrm{mg} / \mathrm{kg})$.

The compound SMe1EC2 (CEM SAS, Bratislava, Slovakia) was administered at the dose of $10 \mathrm{mg} / \mathrm{kg}$ (HFFD-S), and rutin (Rutin hydrate, SigmaAldrich, Slovakia) at the dose of $100 \mathrm{mg} / \mathrm{kg}$ (HFFD-R).
The doses of the substances were based on the literary data. Drugs were dissolved in methylcellulose and administered once a day by gastric gavage in the volume of $0.2 \mathrm{ml} / 100 \mathrm{~g}$ of body weight.

\section{Langendorff apparatus and experimental setting}

The heart was isolated and perfused according to Langendorff and it was under constant perfusion pressure, $80 \mathrm{~mm} \mathrm{Hg}$ (Knezl et al. 2017). Krebs-Henseleit bicarbonate perfusion solution was equilibrated with a gas mixture of $95 \% \mathrm{O}_{2}$ and $5 \% \mathrm{CO}_{2}$ at $37{ }^{\circ} \mathrm{C}$, pH 7.4. A latex balloon (Hugo Sachs Elektronik, Germany) was inserted into the left ventricle filled with water and connected to the pressure transducer (Tesla ElectroManometer, LDP 186, Czechoslovakia) and pressure head (Tesla, LMP 160, Czechoslovakia) to monitor left ventricular pressure. The stimulation electrodes were put on the left ventricle. Heart rate (HR), left ventricular systolic pressure (LVSP), end-diastolic left ventricular pressure (EDLVP), heart product (HP), rate of maximal contraction $\left(+\mathrm{dP} / \mathrm{dt}_{\max }\right)$, rate of maximal relaxation $\left(-\mathrm{dP} / \mathrm{dt}_{\max }\right)$, and coronary flow (CF) were evaluated.

Electrocardiograph (ECG) recording electrodes (Hugo Sachs Elektronik, Germany) were put on the right atrium and apex of the left heart ventricle. ECG was analyzed by BioLab-F (Institute of Measurements, SAS, Slovakia). The electrical activity of the heart was evaluated by PQ, RR, QRS, and QT intervals according to Kralova et al. (2008), QTc interval was calculated according to Kmecova and Klimas (2010). Five consequent recordings of ECG parameters were taken and means were calculated.

The heart was adapted for $15 \mathrm{~min}$ than $20 \mathrm{~min}$ lasting global ischemia was induced (stop-flow), followed by 20 -min reperfusion. Functional parameters of the hearts were measured at the end of stabilization and during reperfusion. The electrical activity of the hearts was measured at the end of stabilization, ischemia, and reperfusion. The meantime of ventricular fibrillation (VF) and ventricular tachycardia (VT) was analyzed and the time to restoration of normal sinus rhythm was monitored.

\section{Immunohistochemistry of NOS3 and NF- $\kappa B$}

The hearts subjected to ischemia/reperfusion (I/R) in all experimental groups were collected to study the possible association between the cardioprotective effect of the compound SMe1EC2 and rutin and changes in the expression of NOS3 and NF- $\mathrm{BB}$. The heart was immersed in the ice-cold Krebs-Henseleit solution and the right ventricle was separated from the left ventricle. 
Subsequently, two parallel transverse incisions were made through the left ventricle by a razor to obtain a $1-2 \mathrm{~mm}$ thick slice of the left ventricle. This slice was fixed in $1 \mathrm{ml}$ of $10 \%$ buffered formalin, embedded in paraffin, and cut into slices $(5 \mu \mathrm{m})$. After the revitalization of heart tissue sections in a citrate epitope retrieval solution $(10 \mathrm{mM}$, pH 6,0) using a water bath with Dako PT Link (Agilent, Santa Clara, California), samples were stained immunohistochemically with murine monoclonal antibody antiNOS3 (Santa Cruz Biotechnology, Dallas, TX) diluted 1:100, and with murine monoclonal antibody anti-NF-kB (Santa Cruz Biotechnology, Dallas, TX) diluted 1:50, then visualized with diaminobenzidine (DAB) and counterstained with hematoxylin. The slices were photographed by a light microscope (Leica DM 2000, Wetzlar, Germany) on 5 random areas for each preparation and the DAB intensity of positivity was evaluated using the computer aided IHC evaluation method as described by Cizkova et al. (2021) using the Fiji (Schindelin et al. 2012) based on ImageJ software (1.51p, National Institutes of Health, USA). The DAB staining intensity was measured as "mean gray value", wherein 0 represents the darkest shade and 255 represents the lightest shade of the colour and was displayed as reciprocal staining intensity (RSI, $\mathrm{RSI}=255-$ mean gray value). The NOS3 and NF- $\mathrm{KB}$ positivity was expressed by semi-quantitative scoring system based on DAB RSI intensity as follows: negative (0) for measured intensities ranking from 0 to 74 , weak (1) for intensities ranking from 75 to 134 , moderate (2) for intensities ranking from 135 to 194 , and strong (3) for intensities higher than 195.

\section{Statistical analysis}

The data were statistically evaluated using Statistica 10, the GraphPad Prism, and the GraphPad InStat software. Data were expressed as means \pm S.E.M. One-way ANOVA was used and the evaluation of differences among experimental groups was done by Bonferroni comparison test. The Kruskal-Wallis nonparametric test followed by Dunn multiple comparisons test was used for the evaluation of differences among experimental groups in immunohistochemistry. The value $p<0.05$ was considered statistically significant.

\section{Results}

Basic biometric data and food consumption of rats exposed to HFFD during 13 weeks and the impact of 5-week-lasted treatment with the compound SMe1EC2 and rutin are given in Table 1. Rats of all groups consumed similar amounts of pellets in $\mathrm{g} / \mathrm{rat} / \mathrm{day}$. Rats fed HFFD had increased energy intake in $\mathrm{kJ} / \mathrm{rat} /$ day compared to rats fed a normal diet due to the higher energy content in HFFD pellets. Increased energy intake was associated with markedly increased liver weight and liver weight/body weight ratio compared to rats fed a normal diet. The impact of HFFD was accompanied by a marked decrease in kidney weight/body weight ratio compared to the control group fed a normal diet. Untreated rats fed HFFD expressed mentioned liver and kidney weight changes, although their body weight gain did not differ compared to the control group. Bodyweight gain increased in both treated groups compared to the control group and compared to HFFD untreated group. The highest increase of body weight gain was found in rats treated with rutin. Cardiac hypertrophy was not found in any group, as the heart weight/body weight ratio was not increased and did not differ among groups.

Functional parameters of isolated and perfused rat hearts were monitored at the end of 15-min stabilization and the end of 20-min reperfusion followed after 20-min ischemia: HR, LVSP, EDLVP, $+\mathrm{dP} / \mathrm{dt}_{\max },-\mathrm{dP} / \mathrm{dt}_{\max }, \mathrm{HP}$, and CF (Table 2). Thirteen-week lasting HFFD followed by 5 -weeks of the normal diet without treatment did not affect markedly the function of the heart neither at stabilization (baseline values) nor during reperfusion (values referred to $\mathrm{I} / \mathrm{R}$ injury) in comparison to the control group fed a normal diet. Five-weeks administration of the compounds tested affected the functional parameters measured of the spontaneously beating rat hearts. The compound SMe1EC2 tended to increase HR, LVSP, HP, and CF baseline values in comparison to the control group fed a standard diet.

During stabilization, EDLVP tended to decrease in HFFD fed group compared to the control group fed a standard diet, and in the rutin treated group it was significantly increased in comparison to HFFD. Rutin tended to increase the EDLVP also throughout the reperfusion comparing to both HFFD untreated and HFFD-S rats. The maximal rate of contraction and relaxation, and their ratio, were not significantly affected by the diet or by treatment. HP tended to be increased at stabilization in the HFFD-S group comparing control and HFFD group. It was however decreased during the whole reperfusion in the HFFD-R group (Fig. 2A). CF was not affected in any experimental group at stabilization, however, it significantly increased at reperfusion $\left(5^{\text {th }}\right.$, $15^{\text {th }}$, and $20^{\text {th }} \mathrm{min}$ ) in the HFFD-S in comparison to the $\mathrm{C}$ group fed a standard diet (Fig. 2B). 
Table 1. Basic biometric data and food consumption of rats exposed to high-fat-fructose diet during a 13 weeks and impact of 5-weeklasted treatment with the compound SMe1EC2 (S) and rutin (R)

\begin{tabular}{|c|c|c|c|c|}
\hline Parameter & $\mathbf{C}$ & HFFD & HFFD-S & HFFD-R \\
\hline \multicolumn{5}{|l|}{ Body weight } \\
\hline At onset, rats $4 w$ old $(g)$ & $49.92 \pm 5.81$ & $48.43 \pm 4.30$ & $44.34 \pm 2.63$ & $41.50 \pm 5.44$ \\
\hline At the end, rats $21 \mathrm{w}$ old $(\mathrm{g})$ & $366.42 \pm 10.60$ & $381.71 \pm 7.32$ & $386.02 \pm 4.82$ & $387.01 \pm 8.40$ \\
\hline Body weight gain $(g)$ & $316.50 \pm 10.61$ & $333.30 \pm 7.25$ & $341.70 \pm 4.76$ & $345.50 \pm 8.43$ \\
\hline Body weight gain (\%) & $634.27 \pm 21.25$ & $688.64 \pm 14.98$ & $771.33 \pm 10.75^{* * *, \#}$ & 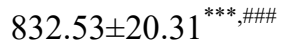 \\
\hline \multicolumn{5}{|l|}{ Food consumption } \\
\hline Pellets intake (g/rat/day) & $20.90 \pm 0.95$ & $21.72 \pm 0.81$ & $22.20 \pm 0.80$ & $21.90 \pm 0.81$ \\
\hline Energy intake (kJ/rat/day) & $299.50 \pm 13.81$ & $352.38 \pm 12.68^{*}$ & $360.04 \pm 12.37^{*}$ & $356.49 \pm 12.20^{*}$ \\
\hline \multicolumn{5}{|l|}{ Liver } \\
\hline Liver weight $(g)$ & $9.66 \pm 0.51$ & $14.03 \pm 0.46^{* * *}$ & $14.29 \pm 0.39^{* * *}$ & $15.05 \pm 0.64^{* * *}$ \\
\hline Liver weight / Body weight (\%) & $2.63 \pm 0.11$ & $3.68 \pm 0.13^{* * *}$ & $3.70 \pm 0.08^{* * *}$ & $3.88 \pm 0.13^{* * *}$ \\
\hline \multicolumn{5}{|l|}{ Heart } \\
\hline Heart weight $(g)$ & $1.14 \pm 0.01$ & $1.23 \pm 0.02$ & $1.19 \pm 0.02$ & $1.15 \pm 0.03$ \\
\hline Heart weight / Body weight (\%) & $0.31 \pm 0.01$ & $0.32 \pm 0.01$ & $0.31 \pm 0.01$ & $0.30 \pm 0.01$ \\
\hline \multicolumn{5}{|l|}{ Kidney } \\
\hline Kidneys weight $(g)$ & $2.15 \pm 0.06$ & $1.95 \pm 0.04^{*}$ & $1.94 \pm 0.03^{*}$ & $1.95 \pm 0.05^{*}$ \\
\hline Kidneys weight / Body weight (\%) & $0.59 \pm 0.01$ & $0.51 \pm 0.02^{* * *}$ & $0.50 \pm 0.01^{* * *}$ & $0.50 \pm 0.01^{* * *}$ \\
\hline
\end{tabular}

All values are expressed as mean \pm SEM. Number of rats per group, $n=10$. Experimental group abbreviations explained in Fig. 1 . $\mathrm{w}$ - week, statistical difference vs. control group * $p \leq 0.05$, *** $p \leq 0.001$, statistical difference vs. HFFD group ${ }^{\#} p \leq 0.05$, ${ }^{\# \# \#} p \leq 0.001$. Statistical significance was determined by ANOVA, Bonferroni comparison test.

Table 2. Functional parameters of isolated rat hearts measured at the end of stabilization (STAB) and at the end of reperfusion (REP) followed after ischemia

\begin{tabular}{|c|c|c|c|c|c|}
\hline \multicolumn{2}{|c|}{ Parameter } & \multirow{2}{*}{$\begin{array}{c}\mathbf{C} \\
285.45 \pm 26.12\end{array}$} & \multirow{2}{*}{$\frac{\text { HFFD }}{279.77 \pm 15.42}$} & \multirow{2}{*}{$\begin{array}{c}\text { HFFD-S } \\
302.18 \pm 27.7\end{array}$} & \multirow{2}{*}{$\begin{array}{c}\text { HFFD-R } \\
289.44 \pm 12.04\end{array}$} \\
\hline Heart rate (HR) & $S T A B$ & & & & \\
\hline (beats/min) & $R E P$ & $254.40 \pm 21.49$ & $272.74 \pm 12.20$ & $286.08 \pm 9.13$ & $250.45 \pm 22.67$ \\
\hline Left ventricular & $S T A B$ & $9.85 \pm 1.41$ & $10.32 \pm 1.59$ & $12.53 \pm 1.00$ & $10.82 \pm 1.43$ \\
\hline $\begin{array}{l}\text { systolc pressure } \\
(L V S P)(k P a)\end{array}$ & $R E P$ & $11.65 \pm 0.31$ & $11.74 \pm 1.02$ & $12.65 \pm 1.33$ & $10.67 \pm 2.54$ \\
\hline $\begin{array}{l}\text { End diastolic left } \\
\text { ventricular }\end{array}$ & $S T A B$ & $0.62 \pm 0.30$ & $0.33 \pm 0.11$ & $0.52 \pm 0.21$ & $1.28 \pm 0.27^{\#}$ \\
\hline $\begin{array}{l}\text { pressure (EDLVP) } \\
(k P a)\end{array}$ & $R E P$ & $0.91 \pm 0.30$ & $0.38 \pm 0.20$ & $0.22 \pm 0.12$ & $1.12 \pm 0.67$ \\
\hline \multirow{2}{*}{$-d P / d t_{\max }(k P a / s)$} & $S T A B$ & $168.33 \pm 29.33$ & $189.71 \pm 33.45$ & $227.56 \pm 18.66$ & $216.30 \pm 39.43$ \\
\hline & $R E P$ & $124.15 \pm 57.21$ & $217.92 \pm 20.94$ & $186.85 \pm 27.26$ & $160.69 \pm 37.54$ \\
\hline \multirow{2}{*}{$+d P / d t_{\max }(k P a / s)$} & $S T A B$ & $249.74 \pm 46.69$ & $271.83 \pm 47.28$ & $316.96 \pm 27.05$ & $267.84 \pm 43.93$ \\
\hline & $R E P$ & $178.63 \pm 78.94$ & $313.16 \pm 30.66$ & $271.99 \pm 37.4$ & $237.16 \pm 52.02$ \\
\hline$-d P / d t_{\max } /$ & $S T A B$ & $0.68 \pm 0.02$ & $0.68 \pm 0.03$ & $0.72 \pm 0.02$ & $0.77 \pm 0.11$ \\
\hline$+d P / d t_{\max }$ & $R E P$ & $0.65 \pm 0.06$ & $0.72 \pm 0.01$ & $0.68 \pm 0.02$ & $0.64 \pm 0.04$ \\
\hline Heart Product & $S T A B$ & $2603.07 \pm 399.26$ & $2947.42 \pm 538.78$ & $3821.26 \pm 459.65$ & $3214.54 \pm 507.63$ \\
\hline $\begin{array}{l}(H P) \\
(k P a \times \text { beats/min) }\end{array}$ & $R E P$ & $2968.86 \pm 307.59$ & $3176.44 \pm 277.93$ & $3614.64 \pm 222.88$ & $2512.15 \pm 579.64$ \\
\hline Coronary flow & $S T A B$ & $9.51 \pm 1.22$ & $10.22 \pm 1.25$ & $12.84 \pm 1.78$ & $11.22 \pm 0.65$ \\
\hline$(C F)(\mathrm{ml} / \mathrm{min})$ & $R E P$ & $9.34 \pm 0.57$ & $11.16 \pm 0.72$ & $14.43 \pm 1.89^{*}$ & $12.00 \pm 1.28$ \\
\hline
\end{tabular}

All values are means $\pm \mathrm{SEM}$. Number of rats per group, $n=10$. Experimental group abbreviations explained in Fig. 1 , significant difference in EDLVP at the end of stabilization ${ }^{*} p<0.05$ HFFD vs. HFFD-R, in CF at reperfusion $* p<0.05$ HFFD-S vs. C, ANOVA, Bonferroni comparison test. 
The electrical activity of hearts determined at stabilization, ischemia, and reperfusion is presented in Table 3. PQ interval was the only one to be significantly affected (shortened) by HFFD in untreated as well as in treated rats at the end of ischemia in comparison to the $\mathrm{C}$ group. The PQ interval was found to be longer at the end of reperfusion only in the HFFD-R group in comparison to the $\mathrm{C}$ group. The QRS complex was significantly shortened at the end of stabilization in the
HFFD-S group in comparison to HFFD fed rats. The HFFD-S group expressed prolonged duration of the QT interval at the end of stabilization in comparison to the $\mathrm{C}$ group, while markedly shortened duration of the QT interval was observed in the HFFD-R group in comparison to the $\mathrm{C}$ group at the end of ischemia. QTc interval duration was longer in both treatments in comparison to the $\mathrm{C}$ group, but only mildly prolonged in the HFFD untreated group at the end of stabilization.
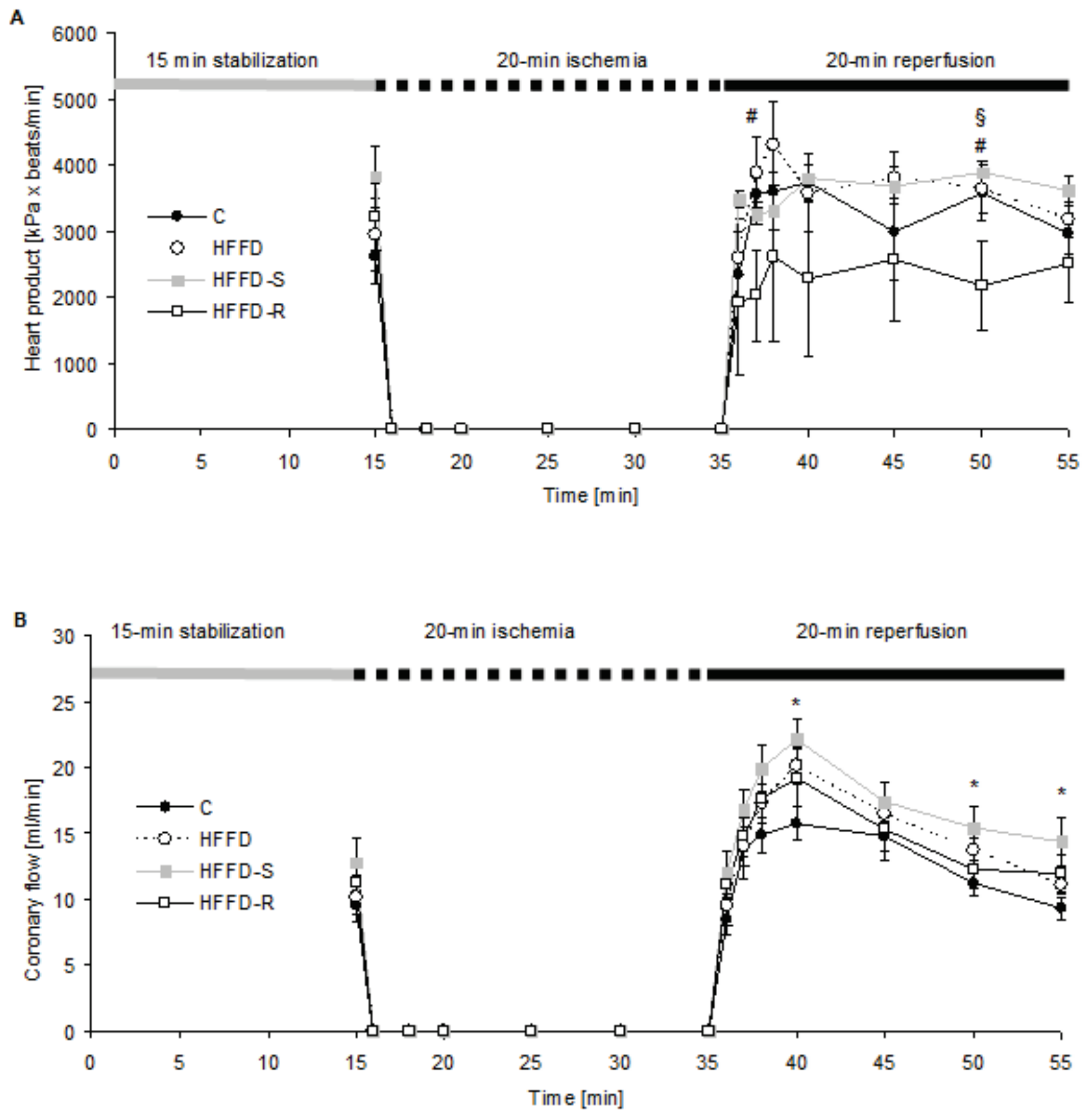

Fig. 2. The heart product (A) and coronary flow (B) course during the whole experiment on rat isolated and perfused hearts exposed to ischemia/reperfusion. The values are means \pm SEM. A number of rats per group, $n=10$. Experimental group abbreviations are explained in Fig. 1. (A) Significant difference at $2^{\text {nd }}$ and $15^{\text {th }}$ min of reperfusion ${ }^{*} p<0.05$ HFFD-R vs. HFFD, ${ }^{\S} p<0.05$ HFFD-R vs. HFFD-S. (B) Significant difference at $5^{\text {th }}, 15^{\text {th }}$ and $20^{\text {th }}$ min of reperfusion ${ }^{*} p<0.05 v s$. C vs. HFFD-S, ANOVA, Bonferroni comparison test. 
Table 3. Rat heart electrical activity determined at stabilization, ischemia, and reperfusion

\begin{tabular}{|c|c|c|c|c|c|}
\hline \multicolumn{2}{|c|}{ Parameter (ms) } & \multirow{2}{*}{$\begin{array}{c}\mathbf{C} \\
45.87 \pm 4.06\end{array}$} & \multirow{2}{*}{$\begin{array}{c}\text { HFFD } \\
50.63 \pm 2.43\end{array}$} & \multirow{2}{*}{$\begin{array}{c}\text { HFFD-S } \\
45.32 \pm 2.69\end{array}$} & \multirow{2}{*}{$\begin{array}{c}\text { HFFD-R } \\
45.48 \pm 4.29\end{array}$} \\
\hline$P Q$ & $S T A B$ & & & & \\
\hline & $I S C H$ & $671.62 \pm 146.28$ & $376.14 \pm 102.16^{*}$ & $259.68 \pm 21.01^{* *}$ & $346.86 \pm 33.35^{* *}$ \\
\hline & $R E P$ & $43.2 \pm 1.56$ & $49.89 \pm 2.52$ & $49.88 \pm 2.97$ & $54.00 \pm 6.12^{*}$ \\
\hline \multirow[t]{3}{*}{$Q R S$} & $S T A B$ & $17.31 \pm 1.48$ & $19.98 \pm 3.91$ & $13.56 \pm 1.07 \#$ & $15.58 \pm 1.06$ \\
\hline & $I S C H$ & $35.43 \pm 3.35$ & $42.29 \pm 7.55$ & $34.43 \pm 5.35$ & $31.14 \pm 5.36$ \\
\hline & $R E P$ & $13.61 \pm 1.21$ & $13.22 \pm 1.02$ & $12.00 \pm 1.35$ & $13.43 \pm 2.91$ \\
\hline \multirow[t]{3}{*}{$R R$} & $S T A B$ & $231.09 \pm 18.03$ & $217.73 \pm 10.73$ & $218.72 \pm 9.41$ & $208.23 \pm 7.21$ \\
\hline & $I S C H$ & $5531.25 \pm 1597.16$ & $2805.53 \pm 483.52$ & $3224.00 \pm 1026.03$ & $3523.14 \pm 1435.07$ \\
\hline & $R E P$ & $273.63 \pm 41.08$ & $223.22 \pm 11.78$ & $231.88 \pm 13.43$ & $238.14 \pm 11.57$ \\
\hline \multirow[t]{3}{*}{$Q T$} & $S T A B$ & $65.86 \pm 7.17$ & $71.03 \pm 6.12$ & $79.54 \pm 2.44^{*}$ & $75.67 \pm 2.71$ \\
\hline & $I S C H$ & $163.61 \pm 13.91$ & $139.03 \pm 21.9$ & $121.71 \pm 6.25$ & $110.04 \pm 8.23^{*}$ \\
\hline & $R E P$ & $61.02 \pm 3.89$ & $53.02 \pm 3.91$ & $57.63 \pm 2.58$ & $57.17 \pm 4.91$ \\
\hline \multirow[t]{3}{*}{$Q T c$} & $S T A B$ & $53.27 \pm 5.33$ & $60.47 \pm 4.37$ & $66.53 \pm 2.26^{*}$ & $64.74 \pm 2.75^{*}$ \\
\hline & $I S C H$ & $26.55 \pm 2.03$ & $31.34 \pm 12.32$ & $32.74 \pm 5.12$ & $31.05 \pm 2.22$ \\
\hline & $R E P$ & $46.76 \pm 4.42$ & $43.8 \pm 3.32$ & $46.58 \pm 2.13$ & $45.44 \pm 4.38$ \\
\hline
\end{tabular}

The values are means \pm SEM. Number of rats per group $n=10$. Experimental group abbreviations explained in Fig. 1 , significant differences vs. C are marked *, significant differences vs. HFFD are marked \#, for end of stabilization (STAB): QRS \# $p<0.05$ HFFD vs. HFFD-S, QT ${ }^{*} p<0.05$ C vs. HFFD-S, QTc ${ }^{*} p<0.05$ C vs. HFFD-S, HFFD-R, for end of ischemia (ISCH): PQ ${ }^{*} p<0.05 \mathrm{C} v s$. HFFD, ${ }^{* *} p<0.005 \mathrm{C}$ vs. HFFD-S, HFFD-R, for end of reperfusion (REP): $\mathrm{PQ}^{*} p<0.05 \mathrm{C} v s$. HFFD-R, ANOVA, Bonferroni comparison test.

NOS3

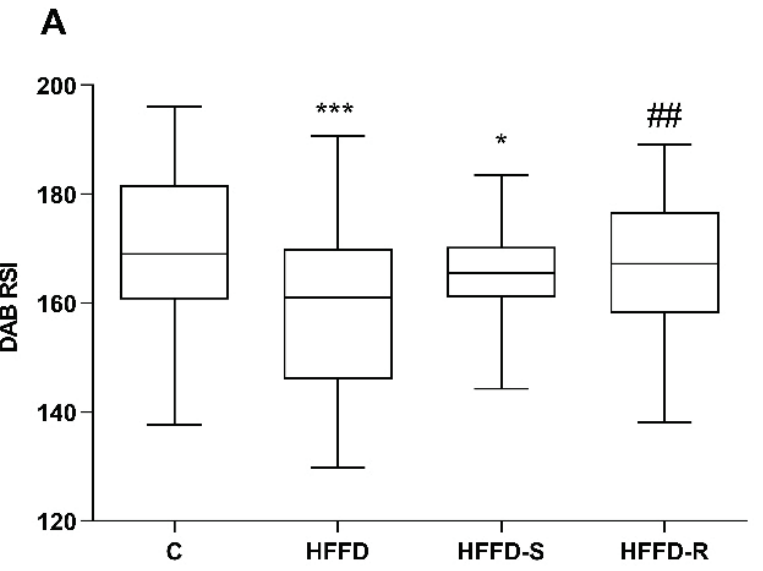

NF-KB

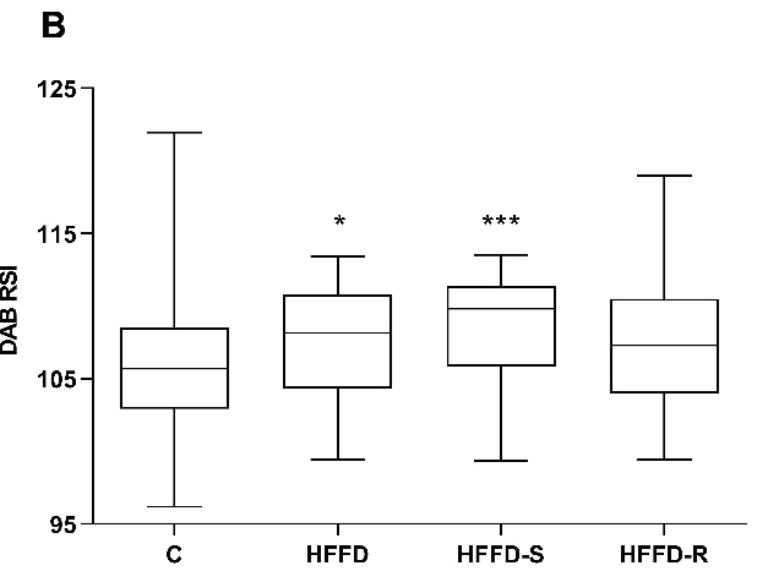

Fig. 3. Immunohistochemical positivity of NOS3 (A) NF-KB (B) in the left heart ventricle. Effect of the treatment with the compound SMe1EC2 and rutin. The values represent 25th to 75th percentile, the whiskers min to max values. A number of rats per group, $n=10$. DAB RSI - diaminobenzidine reciprocal staining intensity. Experimental group abbreviations are explained in Fig. 1. Significant difference at (A) $* * * p<0.001$ for C vs. HFFD, $* p<0.05$ for C vs. HFFD-S, $\# p<0.01$ for HFFD-R vs. HFFD, at (B) $)^{*} p<0.05$ for C vs. HFFD, $* * * p<0.001$ for $\mathrm{C} v$ s. HFFD-S. Kruskal-Wallis test with Dunn multiple comparison test.

Duration of VT did not differ among the positive control HFFD group (78.18 $\pm 22.29 \mathrm{~s})$ and treated groups (HFFD-S 58.84 \pm 32.86 s, HFFD-R 59.66 \pm 17.52 s). Duration of VF was most pronounced in the HFFD-R group $(514.33 \pm 163.44 \mathrm{~s})$ in comparison to the HFFD group $(140.12 \pm 77.18 \mathrm{~s})$. The compound SMe1EC2 significantly lowered the sensitivity of hearts to ventricular arrhythmia induction by electrical stimulation $(30.00 \pm 5.01 \mathrm{~mA})$ in comparison to the untreated HFFD group $(19.00 \pm 1.80 \mathrm{~mA})$. No differences among the groups were observed in the time needed for normal sinus rhythm restoration. 

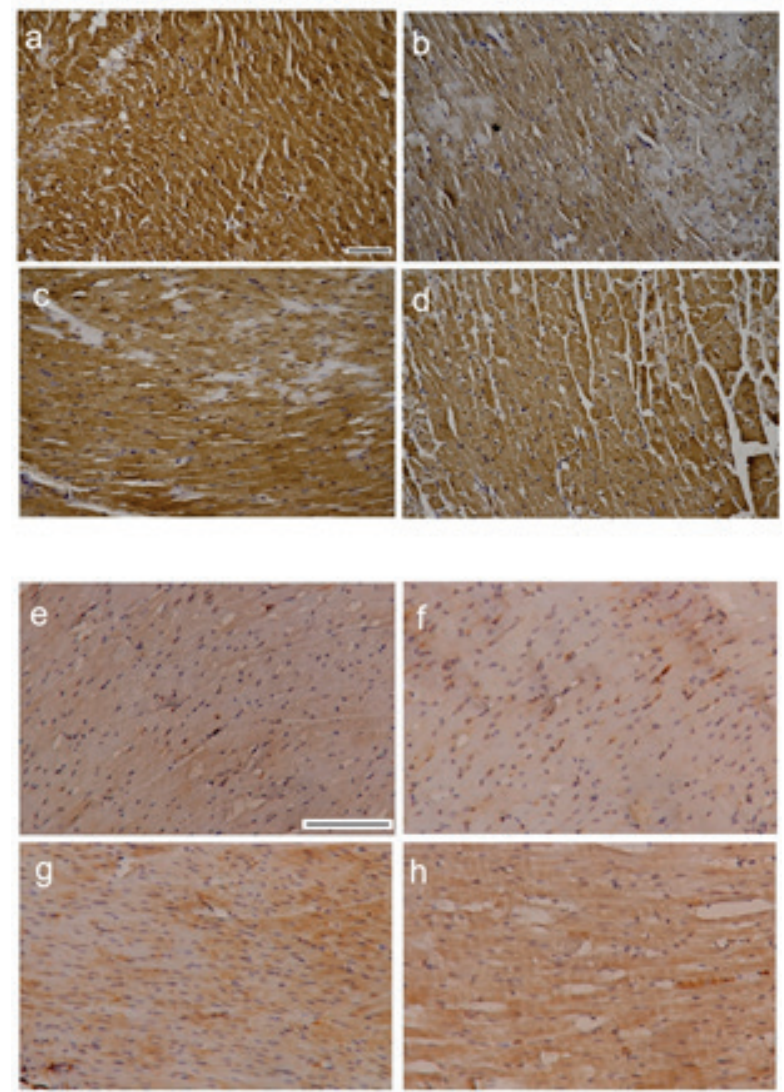

Fig. 4. Representative images of NOS3 and NF-KB immunoreactivity in the left heart ventricle tissue. NOS3 in a) C group, b) HFFD, c) HFFD-S, d) HFFD-R, NF-KB in e) C group, f) HFFD, g) HFFD-S, h) HFFD-R. Experimental group abbreviations are explained in Fig. 1. Scale bar: $100 \mu \mathrm{m}$.

The left ventricle tissue showed moderate cytoplasmic NOS3 and weak NF- $\mathrm{BB}$ positivity in the C group. Significant decreased NOS3 positivity was observed in rats fed with HFFD without treatment compared to the $\mathrm{C}$ group (Fig. 3A, Fig. 4). The compound SMe1EC2 improved NOS3 positivity, and in HFFD-R group it did not differ from rats fed a normal diet. Compared to the controls, increased intensity of NF- $\kappa$ B positivity was found in untreated rats fed HFFD (Fig. 3B, Fig. 4). Treatment with SMe1EC2 resulted in a further increase in the intensity of $\mathrm{NF}-\kappa \mathrm{B}$ positivity. The HFFD-R group did not differ from the untreated group under HFFD.

\section{Discussion}

Feeding hypertriacylglycerolemic rats a high-fatfructose diet deepens the pathological status of animals (Kaprinay et al. 2017, Michalikova et al. 2019, Liptak et al. 2019) and allows the study of the pharmacological possibilities of the individual pathological sign influence.
As OS plays an important role in MetS (Roberts and Sindhu 2009), natural flavonoid rutin and synthetic antioxidant SMe1EC2 were used as potential drugs in the treatment of MetS.

Here, several biometric parameters were affected by HFFD with the impact on liver and kidney weight especially. The increased energy intake induced significant enhancement of the body weight gain and the liver weight /body weight ratio of HTG compared to Wistar rats. We expected that rutin would reduce these parameters because polyphenols generally have a body weight-reducing effect (Boccellino and D'Andelo 2020). In our experiments, however, rutin rather increased the body weight of rats. Similarly, Peng and co-workers (2020) found that rutin had little effect on attenuating obesity, in contrast with its very effective metabolite quercetin. We suppose that the inconsistent effects of rutin result from a different experimental designs used as the rodent species and strain, the composition of dietary fat, the duration of treatment, etc. Among others, the pharmacokinetics of drugs can be changed in HTG rats thereby influencing their effect, these questions need to be studied further. In our experiments, neither the compound SMe1EC2 (10 $\mathrm{mg} / \mathrm{kg})$ depressed the body weight gain. Treatment in combination with the triacylglycerolemia and high-fat-fructose diet in our animal model may affect the rate of metabolism, water retention, etc. which could cause an increase in weight gain, these questions need to be elucidated and studied further. We suppose that the dose may be also a reason for different body weight reducing effects.

One of the key components of MetS is ED which is induced predominantly by decreased NO bioavailability. There are multiple mechanisms for ED when impaired NO availability includes a reduction in NOS3 mRNA or protein expression levels. The function of NOS3 can be affected by altered metabolism due to the MetS (Huang 2009). Decreased NOS3 expression and increased endothelin-1 mRNA expression were reported in the abdominal aorta of rats on a high-fructose diet (Yoo et al. 2017). Indeed, we also observed a large decrease in NOS3 expression in the left ventricle tissue of HTG rats under HFFD.

Both drugs tested significantly upregulated NOS3 expression in the left ventricle tissue. This is under data where rutin promoted NO production in vitro in endothelial cells of the human umbilical vein by inducing NOS3 gene expression, NOS3 protein synthesis, and NOS3 activity (Ugusman et al. 2014). NO itself protects 
the heart against I/R injury, however, in the right ventricle, Boehm and co-authors (2019) demonstrated a profibrotic role for NOS2 induction in the pressureoverload right ventricle and link NOS2-derived excessive NO with right ventricle fibrotic remodeling and promotion of collagen deposition from cardiac fibroblast in mice. It was reported that rutin improved endothelium function through restoring impaired NO generation and ameliorated endothelium contraction/relaxation response in thoracic aorta of rats with a high-glucose diet (Wang et al. 2017). Improvement of endothelial function in experimental models of civilization diseases was observed also by the compound SMe1EC2 previously (Sotnikova et al. 2011, Knezl et al. 2017) which is related to increased NOS3 expression presented here.

Endothelial cells in the heart, present at the endocardium and in the myocardial capillaries, where endothelial cells directly interact with adjacent cardiomyocytes, play an important role in regulating and maintaining cardiac function (Brutsaert 2003). Besides $\mathrm{ED}$, the release of ROS, activation of mitochondrial apoptosis and necrosis, together with chronic low-grade inflammation are the factors contributing to myocardial I/R (Hausenloy and Yellon 2011). These factors are common in the pathology of MetS as well. Present work determined cardiac function in ex vivo induced myocardial I/R injury in MetS rats. Here, the heart functions before ischemia and at the end of reperfusion in rats fed HFFD showed a trend towards increased strength of ventricle contractibility due to the pyridoindole SMe1EC2 (10 mg/kg/5 weeks). However, in the previous study on 8 weeks lasting HFFD, a significant increase in LVSP baseline values was observed by the dose of $25 \mathrm{mg} / \mathrm{kg}$ during 3 weeks treatment (Liptak et al. 2019). It seems that the effect of SMe1EC2 depends not only on the dose but also on the length of the diet $v s$. the length of treatment. During ischemia and inflammation, various endothelium-mediated mediators can cause leukocyte adhesion to the endothelial wall, thereby immobilizing and stimulating neutrophil degranulation. As a result, oxidants and inflammatory mediators are released, leading to tissue damage. Thus it is not surprising that several natural polyphenols have been documented to exert beneficial effects in CVD, including cardiac I/R injury (Ferenczyova et al., 2020). Rutin was reported to have a positive effect on the function of the diabetic myocardium (Guimaraes et al. 2015) and to protect the myocardium from the I/R injury by restoring LVSP, improve the rate of contraction and relaxation, and reduce
LVEDP (Bhandary et al. 2012). However, here, whereas rutin increased EDLVP it did not affect LVSP.

$\mathrm{NF}-\kappa \mathrm{B}$ is found to be chronically active in many inflammatory diseases including also MetS. Elevation of some NF- $\kappa \mathrm{B}$ activators, such as osteoprotegerin, is associated with increased mortality, especially from CVD

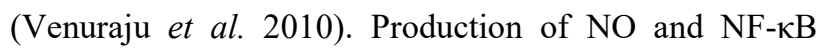
activity interact with each other in endothelial cells. Activation of $\mathrm{NF}-\kappa \mathrm{B}$ reduces NOS3 expression, resulting in decreased NO production and a subsequent increase in $\mathrm{NF}-\kappa \mathrm{B}$ activity and OS (Hasegawa et al. 2012). Increased $\mathrm{NF}-\kappa \mathrm{B}$ expression was reported under pro-inflammatory conditions, such as hyperglycemia (Nishikawa et al. 2000), atherosclerosis (Burcier et al. 1997), and MetS (Itani et al. 2002). It is under our results where HFFD enhanced expression of NF- $\kappa \mathrm{B}$. As OS is positively correlated with the activation of the NF- $\kappa B$ signaling pathway (Liu et al. 2016), the reduction of oxidative stress can lead to the inhibition of NF- $\kappa B$ upregulation. On the other hand, NF- $\kappa \mathrm{B}$ has divergent functions and can contribute to pathogenesis or protect cardiovascular tissues from injury depending on the cellular and physiological condition (Van der Heiden et al., 2010). Inhibition of NF- $\kappa \mathrm{B}$ activity significantly improved heart failure through remodeling the left ventricle, suppressing the expression of the pro-inflammatory cytokines in the infarcted myocardium and contributing to the reduction of fibrosis (Onai et al., 2007). In our results, NF-кB expression was increased due to the compound SMe1EC2 administration and rutin treated group did not differ from the untreated group under HFFD.

In the present work, despite upregulation of NOS3 expression in rutin treated group, the heart function was not significantly affected, and HP showed decreased performance of the isolated perfused heart during reperfusion. A similar observation was reported when a derivative of rutin, quercetin, was inefficient in preventing myocardial I/R injury and worsened vessel relaxation in 1-year-old obese Zucker diabetic fatty rats (Ferenczyova et al. 2020). HP showed a slight improvement in the HFFD-S group at reperfusion and also CF was significantly increased at the beginning of reperfusion. This suggests a better supply of the myocardium and it is an important result suggesting a mechanism of cardiac protection in reperfusion. The 13-week HFFD followed by a 5-week normal diet did not affect the speed of contraction and relaxation, and the impact of change to a normal diet is considered. The important finding is that the compound SMe1EC2 
increased the threshold for VF induction during electrical stimulation. This is following studies confirming its cardioprotective action by reduction of arrhythmia occurrence (Liptak et al. 2019) and a blood pressure decrease of HTG rats under MetS-like condition (Bezek et al. 2017).

Many of the rutin protective effects correlate with its anti-oxidative and anti-inflammatory properties. Quercetin, a derivate of rutin, inhibited xanthine oxidase activity, leading to reduced oxidative damage (Shoskes 1998). Supplementation of 8 weeks by quercetin induced a structural and functional remodeling of resistance coronary artery segments, increased dilatory reserve and augmented NO-mediated endothelial dilation, as well as lowered elastic stress of the rat vessel wall (Monori-Kiss et al., 2017). Administration of the purified flavonoid fraction has been reported to reduce the number of immobilized leukocytes during reperfusion, which may be related to a protective mechanism against inflammatory conditions associated with reperfusion injury (Friesenecker et al. 1994). Another mechanism of endothelium protection is the flavonoid inhibitory effect on LDL oxidation in vitro, thus flavonoids may have a preventive effect against atherosclerosis (Kerry and Abbey 1997).

Administration of HFFD induced a change of the heart electrical activity, which resulted in unexpectedly accelerated signal transmission (PQ interval) and also in both treatments in ischemia, while QT interval was shortened in the HFFD-R group in ischemia, suggesting cardioprotective action. The baseline value of the QTc interval was prolonged in both treatments in comparison to the $\mathrm{C}$ group. Prolonged QTc can be put in correlation to the duration of $\mathrm{VF}$, known as a risk factor for starting life-threatening ventricular arrhythmias (Nachimuthu et al. 2012). Here, the QTc interval was not worsened in $\mathrm{I} / \mathrm{R}$ injury, where increased reactive oxygen production was reported, thus antioxidant and cardioprotective action of both compounds tested can be assumed.

\section{Conclusion}

A high-fat-fructose diet led to a considerable reduction of NOS3 positivity and an increase of NF- $\kappa B$ expression in the left ventricle tissue of hypertriacylglycerolemic rats. Hepatomegaly and decreased kidney weight/body weight ratio were found. The compound SMe1EC2 significantly reduced the sensitivity of the heart to electrically induced ventricular fibrillation. Both SMe1EC2 and rutin, positively affected NOS3 expression in the myocardium comparing to the untreated rats under MetS-like conditions, and partially supported the rat heart function and ECG activity. Despite the observed upregulation of NOS3 by both substances tested, the prospective pyridoindole antioxidant SMe1EC2 rather than rutin proves to be more appropriate in treatment strategies of CVD in MetS-like conditions.

\section{Conflict of Interest}

There is no conflict of interest.

\section{Acknowledgements}

This work was supported by the Scientific Grant Agency of the Ministry of Education, Science, Research and Sport of the Slovak Republic VEGA 2/0054/15 and VEGA 2/0120/19. The authors thank Mrs. Katarina Vandakova, Julia Polakova, and Monika Srnova for their technical assistance.

\section{References}

BEG AA, BALTIMORE D: An essential role of NF-אB in preventing TNF-alpha-induced cell death. Science 274 : 782-784, 1996. https://doi.org/10.1126/science.274.5288.782

BEZEK S, BRNOLIAKOVA Z, SOTNIKOVA R, KNEZL V, PAULOVICOVA E, NAVAROVA J, BAUER V: Monotherapy of experimental metabolic syndrome: I. Efficacy and safety. Interdisc Toxicol 10: 81-85, 2017. https://doi.org/10.1515/intox-2017-0013

BHANDARY B, PIAO CS, KIM DS, LEE GH, CHAE SW, KIM HR, CHAE HJ: The protective effect of rutin against ischemia/reperfusion-associated hemodynamic alteration through antioxidant activity. Arch Pharm Res 35 : 1091-1097, 2012. https://doi.org/10.1007/s12272-012-0617-6

BIERHAUS A, SCHIEKOFER S, SCHWANINGER M, ANDRASSY M, HUMPERT PM, CHEN J, HONG M, LUTHER T, HENLE T, KLOTING I, MORCOS M, HOFMANN M, TRITSCHLER H, WEIGLE B, KASPER M, SMITH M, PERRY G, SCHMIDT AM, STERN DM, HARING HU, SCHLEICHER E, NAWROTH PP: Diabetes-associated sustained activation of the transcription factor nuclear factor-kappaB. Diabetes 50: 2792-2808, 2001. https://doi.org/10.2337/diabetes.50.12.2792 
BOCCELLINO M, D'ANGELO S: Anti-obesity effects of polyphenol intake: Current status and future possibilities. Int J Mol Sci 21: 5642, 2020. https://doi.org/10.3390/ijms21165642

BOEHM, NOVOYATLEVA T, KOJONAZAROV B, VEIT F, WEISSMANN N, GHOFRANI HA, SEEGER W, SCHERMULY RT: Nitric oxide synthase 2 induction promotes right ventricular fibrosis. Am J Respir Cell Mol Biol 60: 346-356, 2019. https://doi.org/10.1165/rcmb.2018-0069OC

BOUDAKA A, AL-SULEIMANI M, AL-LAWATI I, BAOMAR H, AL-SIYABI S, ZADJALI F: Downregulation of endothelial transient receptor potential vanilloid type 4 channel underlines impaired endothelial nitric oxide mediated relaxation in the mesenteric arteries of hypertensive rats. Physiol Res 68: 219-231, 2019. https://doi.org/10.33549/physiolres.933952

BOURCIER T, SUKHOVA G, LIBBY P: The nuclear factor kappa-B signaling pathway participates in dysregulation of vascular smooth muscle cells in vitro and in human atherosclerosis. J Biol Chem 272: 15817-15824, 1997. https://doi.org/10.1074/jbc.272.25.15817

BRUTSAERT DL: Cardiac endothelial-myocardial signaling: Its tole in cardiac growth, contractile performance, and rhytmicity. Phys Rev 83: 59-115, 2003. https://doi.org/10.1152/physrev.00017.2002

CIZKOVA K, FOLTYNKOVA T, GACHECHILADZE M, TAUBER Z: Comparative analysis of immunohistochemical staining intensity determined by light microscopy, ImageJ and QuPath in placental Hofbauer cells. Acta Histochem Cytochem 54: 21-29, 2021. https://doi.org/10.1267/ahc.20-00032

DEANFIELD JE, HALCOX JP, RABELINK TJ: Endothelial function and dysfunction: testing and clinical relevance. Circulation 115: 1285-1295, 2007. https://doi.org/10.1161/CIRCULATIONAHA.106.652859

FERENCZYOVA K, KALOCAYOVA B, KINDERNAY L, JELEMENSKY M, BALIS P, BERENYIOVA A, ZEMANCIKOVA A, FARKASOVA V, SYKORA M, TOTHOVA L, JASENOVEC T, RADOSINSKA J, TOROK J, CACANYIOVA S, BARANCIK M, BARTEKOVA M: Quercetin exerts age-dependent beneficial effects on blood pressure and vascular function, but is inefficient in preventing myocardial ischemiareperfusion injury in Zucker Diabetic Fatty rats. Molecules 25: 187, 2020. https://doi.org/10.3390/molecules25010187

FRIESENECKER B, TSAI AG, ALLEGRA C, INTAGLIETA M: Oral administration of purified micronized flavonoid fraction suppresses leukocyte adhesion in ischemia-reperfusion injury: in vivo observations in the hamster skin fold. Int J Microcirc Clin Exp 14: 50-55, 1994. https://doi.org/10.1159/000178206

GASPAROVA Z, JANEGA P, WEISMANN P, EL FALOUGY H, TYUKOS KAPRINAY B, LIPTAK B, MICHALIKOVA D, SOTNIKOVA R: Effect of metabolic syndrome on neural plasticity and morphology of the hippocampus: correlations of neurological deficits with physiological status of the rat. Gen Physiol Biophys 37: 619-632, 2018. https://doi.org/10.4149/gpb_2018016

GRUNDY SM: Metabolic syndrome: a multiplex cardiovascu $\neg$ lar risk factor. J Clin Endocrinol Metab 92: 399-404, 2007. https://doi.org/10.1210/jc.2006-0513

GUIMARAES JFC, MUZIO BP, ROSA CM, NASCIMENTO AF, SUGIZAKI MM, FERNANDES AAH, CICOGNA AC, PADOVANI CR, OKOSHI MP, OKOSHI K: Rutin administration attenuates myocardial dysfunction in diabetic rats. Cardiovasc Diabetol 14: 90, 2015. https://doi.org/10.1186/s12933-015-0255-7

HASEGAWA Y, SAITO T, OGIHARA T, ISHIGAKI Y, YAMADA T, IMAI J, UNO K, GAO J, KANEKO K, SHIMOSAWA T, ASANO T, FUJITA T, OKA Y, KATAGIRI H: Blockade of the nuclear factor-kappaB pathway in the endothelium prevents insulin resistance and prolongs life spans. Circulation 125: 1122-1133, 2012. https://doi.org/10.1161/CIRCULATIONAHA.111.054346

HAUSENLOY DJ, YELLON DM: The therapeutic potential of ischemic conditioning: An update. Nat Rev Cardiol 8: 619-629, 2011. https://doi.org/10.1038/nrcardio.2011.85

HUANG PL: eNOS, metabolic syndrome and cardiovascular disease. Trends Endocrinol Metab 20: 295-302, 2009. https://doi.org/10.1016/j.tem.2009.03.005

HUANG PL, HUANG Z, MASHIMO H, BLOCH KD, MOSKOWITZ MA, BEVAN JA, FISHMAN MC: Hypertension in mice lacking the gene for endothelial nitric oxide synthase. Nature 377: 239-242, 1995. https://doi.org/10.1038/377239a0 
ITANI SI, RUDERMAN NB, SCHMIEDER F, BODEN G: Lipid induced insulin resistance in human muscle is associated with changes in diacylglycerol, protein kinase C, and IkappaB-alpha. Diabetes 51: 2005-2011, 2002. https://doi.org/10.2337/diabetes.51.7.2005

JURANEK I , HORAKOVA L, RACKOVA L, STEFEK M: Antioxidants in treating pathologies involving oxidative damage: an update on medicinal chemistry and biological activity of stobadine and related pyridoindoles. Review. Curr Med Chem 17: 552-570, 2010. https://doi.org/10.2174/092986710790416317

KAPRINAY B, GASPAROVA Z, LIPTAK B, FRIMMEL K, SOTNIKOVA R: Endothelial dysfunction in experimental models of metabolic syndrome - effect of fructose. Eur Pharm J 64: 4-6, 2017. https://doi.org/10.1515/afpuc-2017-0014

KAPRINAY B, LIPTAK B, SLOVAK L, SVIK K, KNEZL V, SOTNIKOVA R, GASPAROVA Z: Hypertriglyceridemic rats fed high fat diet as a model of metabolic syndrome. Physiol Res 65 Suppl. 4 : S515-S518, 2016. https://doi.org/10.33549/physiolres.933524

KERRY NL, ABBEY M: Red wine and fractionated phenolic compounds prepared from red wine inhibit low density $\begin{array}{llllll}\text { lipoprotein oxidation in } & \text { vitro. } \quad \text { Atherosclerosis }\end{array}$ https://doi.org/10.1016/S0021-9150(97)00156-1

KMECOVA J, KLIMAS J: Heart rate correction of the QT duration in rats. Eur J Pharmacol 641: 187-192, 2010. https://doi.org/10.1016/j.ejphar.2010.05.038

KNEZL V, SOTNIKOVA R, BRNOLIAKOVA Z, STANKOVICOVA T, BAUER V, BEZEK S: Monotherapy of experimental metabolic syndrome: II. Study of cardiovascular effects. Interdisc Toxicol 10: 86-92, 2017. https://doi.org/10.1515/intox-2017-0014

KRALOVA E, MOKRAN T, MURIN J, STANKOVICOVA T: Electrocardiography in two models of isoproterenolinduced left ventricular remodeling. Physiol Res $57 \quad$ Suppl 2: S83-89, 2008. https://doi.org/10.33549/physiolres.931556

KRISHNA KM, ANNAPURNA A, GOPAL GS, CHALAM CRV, MADAN K, KUMAR VK, PRAKASH GJ: Partial reversal by rutin and quercetin of impaired cardiac function in streptozotocin-induced diabetic rats. Canad $\mathrm{J}$ Physiol Pharmacol 83: 343-355, 2005. https://doi.org/10.1139/y05-009

LIPTAK B, KNEZL V, GASPAROVA Z: Anti-arrhythmic and cardio-protective effects of atorvastatin and a potent pyridoindole derivative on isolated hearts from rats with metabolic syndrome. Bratisl Med J 120: 200-206, 2019. https://doi.org/10.4149/BLL 2019 034

LIU X, LIN R, ZHAO B, GUAN R, LI T, JIN R: Correlation between oxidative stress and the NF $\kappa$ B signaling pathway in the pulmonary tissues of obese asthmatic mice. Mol Med Rep 13: 1127-1134, 2016. https://doi.org/10.3892/mmr.2015.4663

LV L, YAO Y, ZHAO G, ZHU G: Rutin inhibits coronary heart disease through ERK1/2 and Akt signaling in a porcine model. Exp Ther Med 15: 506-512, 2018. https://doi.org/10.3892/etm.2017.5365

MICHALIKOVA D, TYUKOS KAPRINAY B, LIPTAK B, SVIK K, SLOVAK L, SOTNIKOVA R, KNEZL V, GASPAROVA Z: Natural substance rutin versus standard drug atorvastatin in a treatment of metabolic syndrome-like condition. Saudi Pharm J 27: 1196-1202, 2019. https://doi.org/10.1016/j.jsps.2019.10.002

MONORI-KISS A, KISS F, RESTIFO JM, MONOS E, NADASY GL: Chronic administration of quercetin induces biomechanical and pharmacological remodeling in the rat coronary arteries. Physiol Res 66: 591-599, 2017. https://doi.org/10.33549/physiolres.933384

NACHIMUTHU S, ASSAR MD, SCHUSSLER JM: Drug-induced QT interval prolongation: mechanisms and clinical management. Ther Adv Drug Res 3: 241-253, 2012. https://doi.org/10.1177/2042098612454283

NISHIKAWA T, EDELSTEIN D, DU XL, YAMAGISHI S, MATSUMURA T, KANEDA Y, YOREK MA, BEEBE D, OATES PJ, HAMMES HP, GIARDINO I, BROWNLEE M: Normalizing mitochondrial superoxide production blocks three pathways of hyperglycaemic damage. Nature 404: 787-789, 2000. https://doi.org/10.1038/35008121

ONAI Y, SUZUKI J, MAEJIMA Y, HARAGUCHI G, MUTO S, ITAI A, ISOBE M: Inhibition of NF-kappaB improves left ventricular remodeling and cardiac dysfunction after myocardial infarction. Am J Physiol Heart Circ Physiol 292: H530-H538, 2007. https://doi.org/10.1152/ajpheart.00549.2006 
PARSANATHAN R, JAIN SK: Novel invasive and noninvasive cardiac-specific biomarkers in obesity and cardiovascular diseases. Metab Syndr Relat Disord 18: 10-30, 2020. https://doi.org/10.1089/met.2019.0073

PENG L, YHANG Q, ZHANG Y, YAO Z, SONG P, WEI L, ZHAO G, YAN Z: Effect of tartary buckwheat, rutin, and quercetin on lipid metabolism in rats during high dietary fat intake. Food Sci Nutr 8: 199-213, 2020. https://doi.org/10.1002/fsn3.1291

PRINCE P, KAMALAKKANNAN N: Rutin improves glucose homeostasis in streptozotocin diabetic tissues by altering glycolytic and gluconeogenic enzymes. J Biochem Mol Toxicol 20: 96-102, 2006. https://doi.org/10.1002/jbt.20117

REAVEN GM: Banting lecture 1988. Role of insulin resistance in human disease. Diabetes 37: 1595-1607, 1988. https://doi.org/10.2337/diabetes.37.12.1595

ROBERTS CK, SINDHU KK: Oxidative stress and metabolic syndrome. Life Sci 84: 705-712, 2009. https://doi.org/10.1016/j.lfs.2009.02.026

SCHINDELIN J, ARGANDA-CARRERAS I, FRISE E, KAYNIG V, LONGAIR M, PIETZSCH T, PRIBISCH S, RUEDEN C, SAALFELD S, SCHMID B, TINEVEZ J-Y, WHITE DJ, HARTENSTEIN V, ELICEIRI K, TOMANCAK P, CARDONA A: Fiji: An open-source platform for biological-image analysis. Nature Methods 9: 676-682, 2012. https://doi.org/10.1038/nmeth.2019

SHOSKES DA: Effect of bioflavonoids quercetin and curcumin on ischemic renal injury: a new class of renoprotective agents. Transplantation 66: 147-152, 1998. https://doi.org/10.1097/00007890-199807270-00001

SOTNIKOVA R, NEDELCEVOVA J, NAVAROVA J, NOSALOVA V, DRABIKOVA K, SZOCS K, KRENEK P, KYSELOVA Z. BEZEK S, KNEZL V, DRIMAL J, BROSKOVA Z, KRISTOVA V, OKRUHLICOVA L, BERNATOVA I, BAUER V: Protection of the vascular endothelium in experimental situations. Interdiscip Toxicol 4: 20-26, 2011. https://doi.org/10.2478/v10102-011-0005-y

STOLC S, SNIRC V, MAJEKOVA M, GASPAROVA Z, GAJDOSIKOVA A, STVRTINA S: Development of the new group of indole-derived neuroprotective drugs affecting oxidative stress. Cell Mol Neurobiol 26: 1495-1504, 2006. https://doi.org/10.1007/s10571-006-9037-9

UGUSMAN A, ZAKARIA Z, CHUA KH, NORDIN NA, MAHDY ZA: Role of rutin on nitric oxide synthesis in human umbilical vein endothelial cells. Sci World J 2014: 169370, 2014. https://doi.org/10.1155/2014/169370

VAN DER HEIDEN K, CUHLMANN S, LUONG LA, ZAKKAR M, EVANS PC: Role of nuclear factor kappaB in cardiovascular health and disease. Clin Sci (Lond) 118: 593-605, 2010. https://doi.org/10.1042/CS20090557

VENURAJU SM, YERRAMASU A, CORDER R, LAHIRI A: Osteoprotegerin as a predictor of coronary artery disease and cardiovascular mortality and morbidity. J Am Coll Cardiol 55: 2049-2061, 2010. https://doi.org/10.1016/j.jacc.2010.03.013

WANG W, WU QH, SUI Y, WANG Y, QIU X: Rutin protects endothelial dysfunction by disturbing Nox4 and ROSsensitive NLRP3 inflammasome. Biomed Pharmacother 86: 32-40, 2017. https://doi.org/10.1016/j.biopha.2016.11.134

YOO SY, AHN H, PARK YK: High dietary fructose intake on cardiovascular disease related parameters in growing rats. Nutrients 9: 11, 2017. https://doi.org/10.3390/nu9010011

ZICHA J, PECHANOVA O, CACANYOVA S, CEBOVA M, KRISTEK F, TOROK J, SIMKO F, DOBESOVA Z, KUNES J. Hereditary hypertri-glyceridemic rat: a suitable model of cardiovascular disease and metabolic syndrome? Physiol Res 55: 49-63, 2006. 